\title{
Movement behavior of the Monito del monte (Dromiciops gliroides): new insights into the ecology of a unique marsupial
}

\author{
Lida M. Franco ${ }^{1+} \mathbb{D}$, Francisco E. Fontúrbel ${ }^{2^{*}+} \mathbb{D}$, Giovany Guevara ${ }^{3}$ (D) and Mauricio Soto-Gamboa ${ }^{4}$
}

\begin{abstract}
Background: Behavior and activity patterns largely determine animal's fitness and their ecological roles. Those patterns depend on many factors, being body mass, sex and age the most relevant in mammals. Particularly, those factors altogether with environmental conditions could influence movement behavior of mammals that hibernate, such as the Monito del monte (Dromiciops gliroides).
\end{abstract}

Methods: To evaluate its movement behavior and activity we radio-tracked D. gliroides 12 individuals ( 8 females and 4 males, corresponding to 5 adults and 7 sub-adults) during the austral summer. With the estimated locations we estimated home ranges, core areas and their relationship with body mass. We also assessed movement speed during early (19:00 to 01:00 h), peak (01:00 to 03:00 h) and late (03:00 to 07:00 h) activity periods. This study was conducted at the San Martín experimental forest (Valdivia, southern Chile).

Results: Estimated home range areas were $1.04 \pm 0.20 \mathrm{ha}$, and core areas were $0.27 \pm 0.06 \mathrm{ha}$; we found no significant differences between males and females, nor between adults and sub-adults. Home range and core areas were independent of body mass in females but showed positive relationships in males. Core area overlap was larger between sub-adult and adult individuals (35\%) than between adult males and females (13\%). Average movement $D$. gliroides speed was $1.45 \mathrm{~m} / \mathrm{min}$, reaching its lowest value during the peak activity period (01:00 to 03:00 h), but being faster during early and late activity periods. Those speed differences may be related to travelling and foraging activities.

Conclusion: Home range and core areas estimated here showed a large variability, which can be related to environmental factors. Home range size was positively correlated with body mass on males but not on females. Also, lower movement speeds at the peak activity period suggest that D. gliroides concentrates feeding activities at this time. As D. gliroides disperses the seeds of at least 16 native plant species, its movement behavior also has important consequences at the community level.

Keywords: Body mass, Core area, Dromiciops gliroides, Home range, Monito del monte, Movement speed, Southern Chile

\footnotetext{
*Correspondence: fonturbel@gmail.com; http://orcid.org/0000-0001-8585-

2816,

${ }^{\dagger}$ Lida M. Franco and Francisco E. Fontúrbel contributed equally to this work.

${ }^{2}$ Instituto de Biología, Pontificia Universidad Católica de Valparaíso, Av.

Universidad 330, 2373223 Valparaíso, Chile

Full list of author information is available at the end of the article
}

(c) The Author(s). 2019 Open Access This article is distributed under the terms of the Creative Commons Attribution 4.0 International License (http://creativecommons.org/licenses/by/4.0/), which permits unrestricted use, distribution, and reproduction in any medium, provided you give appropriate credit to the original author(s) and the source, provide a link to the Creative Commons license, and indicate if changes were made. The Creative Commons Public Domain Dedication waiver (http://creativecommons.org/publicdomain/zero/1.0/) applies to the data made available in this article, unless otherwise stated. 


\section{Background}

Animal behavior is the result of evolutionary processes that determine how individuals of a given species use the environment and interact with their conspecifics and other species [1]. Therefore, behavioral patterns are a phenotypic expression of the genome, involving heritable but also highly plastic traits [2, 3]. Consequently, this behavioral expression largely determines animal fitness as well as its ecological roles in the ecosystem, considering that the environment is highly dynamic in terms of and resource availability $[4,5]$. Spatial behavior, therefore, may be strongly correlated to morphological (body mass), physiological (metabolic rate), ecological (intra- and interspecific interactions, diet and foraging strategies), social, and environmental factors [6, 7]. Information on spatial behavior in wild animals is difficult to obtain (and particularly for cryptic species), but is important for understanding their home range, social interactions, mating systems and foraging strategies [8]. Such behavior depends on energy requirements, locomotion, habitat productivity, body mass and sex ratio [9]. Small mammals that hibernate usually have discrete activity periods in which they face energy constraints, in response to seasonal and daily changes in environmental factors such as temperature, rainfall, photoperiods, and food availability [10]. These adverse conditions could be compensated through decreased activity and increased daily torpor under colder conditions $[11,12]$.

Among small mammals that hibernate there is the Monito del monte, Dromiciops gliroides (Thomas 1894), a nocturnal arboreal marsupial, considered a living fossil as it is the only living representative of the ancient Order Microbiotheria, and the only species of the Australidelphia Superorder present in South America [13]. This marsupial is endemic to southern Chile and adjacent areas in Argentina, inhabiting in the South American temperate rainforests of northern Patagonia. Recent studies showed that space use (i.e., home range areas and habitat selection patterns) by D. gliroides is highly consistent regardless of the forest condition and location $[14,15]$, even in exotic tree plantations [16]. However, many aspects of $D$. gliroides behavioral ecology remain unexplored. Given that home range size is mainly explained by body mass across mammal species [7] and environmental features [17], we tested whether D. gliroides body mass, sex [females are larger and heavier than males; 14], and age explains the variation in home range and core area sizes. We used a sequential hypothesis framework. Firstly, we predict that larger individuals (i.e., females and adults) will use larger areas. Secondly, we tested whether the overlap between adult males and females differs from that between adults and sub-adults. Here we predict that core area overlap will be larger between adults and sub-adults than between males and females because of the presence of family groups [18]. Thirdly, because camera-trapping efforts [19] obtained the greatest number of observations between 01:00 and 03:00 h, we predict that $D$. gliroides individuals would move faster during this peak activity period.

\section{Methods}

\section{Study area}

We performed this study at the San Martín Experimental Forest $\left(39^{\circ} 41^{\prime} \mathrm{S}, 73^{\circ} 18^{\prime} \mathrm{W}\right)$, an 80 -ha land owned by Universidad Austral de Chile, located $80 \mathrm{~km}$ north of Valdivia (southern Chile). Ambient temperatures range from $18 \pm 1^{\circ} \mathrm{C}$ in the austral summer (February) and $7 \pm$ $1{ }^{\circ} \mathrm{C}$ in the winter (July). Mean annual precipitation is $2205 \mathrm{~mm}$ (ranging between 1500 and $3000 \mathrm{~mm}$ ), concentrated in the austral fall (April-June) and winter (JuneSeptember) [20]. San Martín is a relict fragment of the Valdivian temperate rainforest [21], an ecosystem considered to be biologically unique and critically endangered $[22,23]$. This experimental forest is a secondary-growth stand dominated by the evergreen trees Gevuina avellana, Drimys winteri, Laurelia sempervirens, Embothrium coccineum, Luma apiculata, Amomyrtus meli, altogether with sparse old Nothofagus spp. trees and the native bamboo Chusquea valdiviensis [24].

\section{Data collection}

We captured $D$. gliroides individuals at the study site using custom-made, single-door, Tomahawk-like wiremesh live traps $(26 \times 13 \times 13 \mathrm{~cm})$. Traps were placed 1-2 $\mathrm{m}$ above ground level and baited with fresh banana slices [see 25,26$]$. We set 144 traps in a web-style trapping grid, consisting in 12 radiating lines of 12 traps at $10 \mathrm{~m}$ intervals [27]. Trapping grids were monthly operated over ten consecutive days each month from December 2008 to April 2009 (total trapping effort = 3600 trapnights), avoiding full moon nights. Traps were checked daily at dawn and animals were released at the capture site after processing. We recorded body mass (using a Pesola ${ }^{\circ}$ spring scale), standard morphometric measurements (total length, tail length, and nose tip to tail base length), sex (based on a visual inspection of the reproductive organs), and age (adult or sub-adult) for each captured individual. To differentiate adults from sub-adults we used the criteria of Salazar and Fontúrbel [16], being adults those individuals with body mass $>24$ $g$ and nose tip-to-tail length larger than tail length, and sub-adults those individuals with body mass $\leq 24 \mathrm{~g}$ and nose tip-to-tail length shorter than tail length. Capturing and handling procedures followed the guidelines of the American Society of Mammalogists [Sikes et al. 28], and were authorized by the Chilean Agriculture and Livestock Bureau (SAG; permits 161-2006 and 146-2008 granted to LMF). 
During the austral summer (January to March) of 2009, 18 D. gliroides individuals were captured. Twelve of those individuals (three adult and one sub-adult males, and two adults and six sub-adults females) were fitted with telemetry transmitters (Biotrack ${ }^{\circ}$ United Kingdom, cable-tie collars of $0.9 \mathrm{~g}$, representing $\leq 5 \%$ of the body mass) and intensively tracked from dusk to dawn on a daily basis between 23-Jan and 12-Apr (we have not tracked individuals during rainy nights). Two teams (communicated with handy radios) simultaneously located each individual and registered the geographic coordinates (i.e., GPS position), bearing, time and signal strength to minimize data collection error. Noise and lights were kept to minimum to avoid disturbing the tracked animals. Before taking animal locations we conducted a field test, in which one person placed transmitters with known locations and then were tracked by other people (unaware of the real location) to assess estimation error, which was below $5 \mathrm{~m}$.

\section{Data analysis}

We estimated actual locations of the tracked individuals by grouping bearings taken in the field in groups of three or four bearings taken within a 10-min interval, and separated at least by $20^{\circ}$ [although we privileged groups with separations between $45^{\circ}$ and $135^{\circ}$ to reduce triangulation error; 29, 30]. We estimated locations using the software LOAS 4.0 (Ecological Software Solutions, Switzerland), considering a minimum of $30 \mathrm{~min}$ between relocations of the same individual to ensure data independence. Error ellipses average values ranged from 0.01 to 0.06 ha. Using the estimated locations, we calculated core areas and home range areas of the tracked D. gliroides individuals using the 50 and $90 \%$ kernel density estimators (KDE hereafter), respectively [15]. Core and home range areas were obtained with the adehabitatHR package [31] in R 3.5.0 [32], using a least square cross validation (LSCV) method for defining kernel bandwidth. In order to assess the robustness of the home range and core areas estimated in function of the number of telemetry locations used, we took the individual with the largest number of locations (individual M01 with 119 locations), and we made 45 location files with random subsets of 5 to 50 locations. Then we estimated home range and core areas for each location subset and compared them with the real values.

We compared body mass between males and females and between adults and sub-adults using generalized linear models (GLM) with a Gaussian error distribution. Likewise, we compared KDE home range and core area sizes between males and females, as well as between adults and sub-adults using GLMs. Then, we fitted additional GLM models to assess the relationship between home range and core area sizes with body mass and the number of locations; we assessed all individuals together first, and then we assessed males and females, and adults and sub-adults separately. Normality and variance structure were checked for each model fitted [33]. We also assessed the extent of overlap in core areas (i.e., KDE $50 \%$ ) between adult males and females, and between adult and sub-adult individuals, using Cartographica 1.4.9 (ClueTrust, Reston VA) GIS software. For this purpose, we merged individual core areas for each group (i.e., males vs. females, adults vs. sub-adults) before conducting the overlap analysis to focus the comparison on the groups and not on the individuals.

Using estimated locations, we then calculated the distance between successive points within a 120 -min period as a proxy of movement behavior. We considered three different activity time periods [following 19; based on camera-trap records]: (a) early activity from 19:00 to 01 : $00 \mathrm{~h},(\mathrm{~b})$ activity peak from 01:01 to 03:00 h, and (c) late activity from 03:01 to 07:00 h. Then, we estimated individual movement speed as the ratio between distance and time differences between consecutive locations (expressed in meters moved per minute). In order to determine if movement behavior changes in function of the activity period (early, peak and late) we performed a mixed-effects generalized linear model (GLMM) with a Gaussian error distribution, using movement speed as a response variable, the activity period as a fixed factor, and the tracked individual id as a random factor to account for inter-individual variability [34]. GLMM parameters and their significance were estimated using restricted maximum likelihood (REML) $t$-tests, with a Kenward-Roger approximation to degrees of freedom [35]. Values are presented as mean $\pm 1 S E$ unless otherwise indicated. GLM and GLMM results in the main text are presented using $t$ - and $P$-values obtained, while estimates for each variable and their standard error are presented in the Supporting Information available online. GLMs and GLMMs were implemented in R 3.5.0 [32] using the packages lme4 [36], lmerTest [37], and pbkrtest [35], illustrations were developed using ggplot2 [38].

\section{Results}

Tracked individuals differed in body mass, with females $(26.2 \pm 3.1 \mathrm{~g})$ heavier than males $(24.6 \pm 2.4 \mathrm{~g})$ (GLM comparison, $t=-3.55, P<0.01)$, and adults $(32.4 \pm 2.5 \mathrm{~g})$ heavier than sub-adults $(20.0 \pm 0.5 \mathrm{~g})(t=-9.42, P<0.01$; detailed GLM results are available in Additional file 1: Table S1). We obtained a total of 652 locations ( $54 \pm 12$ locations per individual) for the tracked $D$. gliroides individuals. Core areas (KDE at 50\%) ranged from 0.05 to 0.64 ha $(0.27 \pm 0.06$ ha) whereas home ranges (KDE at $90 \%)$ ranged from 0.16 to 2.20 ha $(1.04 \pm 0.20$ ha; Table 1). Our results show that home range estimations 
Table 1 Descriptive information of the tracked Dromiciops gliroides individuals (gender, age and body mass). The number of telemetry locations estimated for each individual is showed together with core areas (KDE 50\%, in ha) and home ranges (KDE 90\%, in ha)

\begin{tabular}{lllllll}
\hline ID & Gender & Age & Mass (g) & Locations & CA (ha) & HR (ha) \\
\hline F03 & Female & Adult & 39.0 & 27 & 0.38 & 1.59 \\
F07 & Female & Adult & 36.0 & 103 & 0.14 & 0.65 \\
F02 & Female & Sub-adult & 21.0 & 27 & 0.06 & 0.23 \\
F04 & Female & Sub-adult & 18.5 & 27 & 0.61 & 2.20 \\
F05 & Female & Sub-adult & 19.5 & 27 & 0.10 & 0.40 \\
F06 & Female & Sub-adult & 20.8 & 21 & 0.14 & 0.46 \\
F08 & Female & Sub-adult & 21.0 & 20 & 0.64 & 1.89 \\
F01 & Female & Sub-adult & 21.0 & 88 & 0.30 & 1.06 \\
M01 & Male & Adult & 32.8 & 119 & 0.29 & 1.46 \\
M02 & Male & Adult & 27.0 & 124 & 0.30 & 1.52 \\
M03 & Male & Adult & 27.0 & 42 & 0.21 & 0.82 \\
M04 & Male & Sub-adult & 18.0 & 27 & 0.05 & 0.16 \\
& & Mean & $\mathbf{2 5 . 1}$ & $\mathbf{5 4 . 3}$ & $\mathbf{0 . 2 7}$ & $\mathbf{1 . 0 4}$ \\
& & SE & $\mathbf{2 . 1}$ & $\mathbf{1 1 . 9}$ & $\mathbf{0 . 0 6}$ & $\mathbf{0 . 2 0}$ \\
\hline
\end{tabular}

became stable at $\sim 30$ locations, after this value adding more locations have a negligible effect on the home range and core area values obtained (Additional file 1: Figure S1).

Neither home range nor core areas differed between males and females $(0.99 \pm 0.32$ versus $1.06 \pm 0.26$ ha, $t=$ $-0.55, P=0.59$ for home range; $0.21 \pm 0.06$ versus $0.30 \pm 0.08$ ha, $t=-0,72, P=0.49$ for core area), or between adults and sub-adults $(1.21 \pm 0.19$ versus $0.91 \pm$ 0.31 ha, $t=-0.87, P=0.41$ for home range; $0.26 \pm 0.04$ versus $0.27 \pm 0.10$ ha, $t=-0.30, P=0.77$ for core area; detailed GLM results are available in Additional file 1: Table S2; individual home range and core areas are presented in Additional file 1: Figures S2 and S3, respectively). Home range and core area size did not vary according to body mass in any case $(t=0.68, P=0.51$ for home range; $t=0.07, P=0.95$ for core area; detailed GLM results are available in Additional file 1: Table S3). Further, neither home range $(t=0.53, P=0.61)$ nor core area $(t=-0.18, P=0.86)$ sizes varied in function to the number of telemetry locations (detailed GLM results are available in Additional file 1: Table S4), except for home range area in males, which showed a marginally significant $(P=0.049)$ relationship. Core area overlap between adult males and females was $12.7 \%$ (Additional file 1 : Figure S4), whereas the overlap between adult and subadult individuals was 35.5\% (Additional file 1: Figure S5).

Movement speed ( $\mathrm{m}$ per minute) significantly varied among activity periods $(t=9.14, \quad P<0.001$; detailed GLMM results are available in Additional file 1: Table S5), reaching its highest value at the early period, its lowest value at the peak period, and an intermediate value at the late period. Movement speed at the late period was statistically different from the early period but not from the peak period (Fig. 1).

\section{Discussion}

Our tracked D. gliroides individuals showed a large variability in spatial behavior. We found no significant differences between home ranges or core areas of males and females, nor between adults and sub-adults. This was despite Dromiciops gliroides female individuals being larger and heavier than males, and adults were larger and heavier than sub-adults. This result suggests that other variables (e.g., food availability, environmental conditions, predation risk) may be more important than body mass for defining home range size in this species. Particularly, females might be establishing home range sizes independently of their body mass. In this case it might be determined by food gathering and their higher protein requirement for reproduction, related to postreproductive period, parental care and the need to ensure that juveniles grow rapidly to gain sufficient weight and survive their first winter during the hibernation period [18].

Likewise, we found no differences between adult and sub-adult individuals despite being a large body mass difference. In other marsupial species, sub-adults showed large home ranges than adults. In those cases, males and juveniles of some mammal species exhibit greater movement related to foraging and mating behavior [39]. Home range and core areas estimated for $D$. gliroides in this study were similar to those reported by previous studies on this species in different localities of Argentina and Chile [14-16]. This similarity across a large spatial extent suggests that spatial movement is a highly repeatable behavioral trait in this species, irrespective to its location or particular habitat conditions.

Fontúrbel et al. [19] showed that activity in D. gliroides starts at 19:00 $\mathrm{h}$ and lasts until 07:00 $\mathrm{h}$ during the austral summer, with an activity peak between 01:00 to 03:00 $\mathrm{h}$ (i.e., the time period concentrating most of the photographic records). Based on those observations by Fontúrbel et al. [19] we predicted that $D$. gliroides would move faster during the presumed peak in activity from 01:00 to 03:00 h. In contrast, however, tracked individuals moved faster at the beginning of its activity period, showing the lowest movement speed at the peak activity period. We believe that this reflects greater foraging activity during the peak activity period [40]. We expected $D$. gliroides to move more during this period as it concentrates most of camera-trap observation [19], but finding the opposite suggests that such time frame is devoted to feeding activities. Further, moving longer distances during the early activity period (when there is more light at dusk, and hence more exposure to predators) 


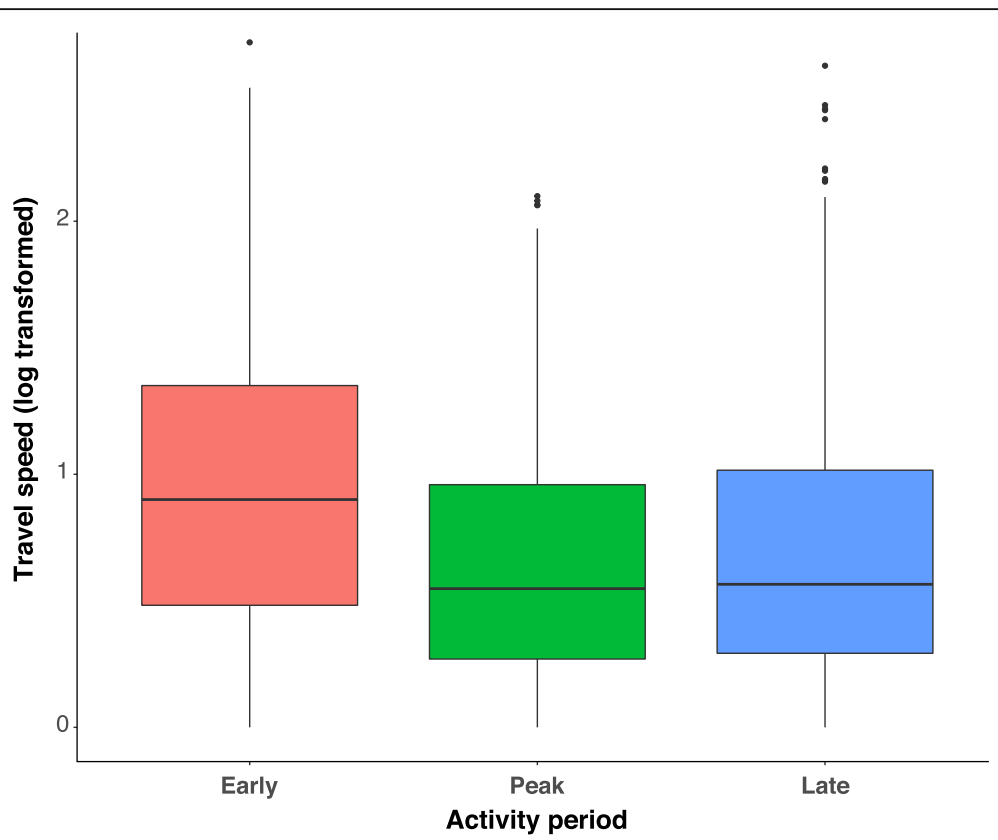

Fig. 1 Travel speed (m / min) during the early (19:00 to 01:00 h), peak (01:00 to 03:00 h), and late (03:00 to 07:00 h) activity periods

could be related to round trips from nesting to feeding sites. In addition, hibernating smalls mammals like $D$. gliroides are expected to be more active when environmental conditions are favorable [i.e., austral summer; 11]. These findings are consistent with the movement velocity estimations by di Virgilio et al. [41], who found that D. gliroides move faster after sunset and before sunrise, based on videos obtained using camera-traps, supporting our inference of rapid movement during travel to foraging sites.

Studying movement behavior is also important to understand other ecological processes such as feeding behavior. Dromiciops gliroides is a generalist frugivore with a key ecosystem role as the primary seed disperser of at least 16 native plant species [42, 43]. Thus, its spatial behavior also should have community-level consequences as both home range and movement speed largely determines seed deposition patterns $[44,45]$. Taking the mistletoe Tristerix corymbosus as the most significant example, as it is only dispersed by $D$. gliroides below $37^{\circ} \mathrm{S}$ [46], and using the time budget and feeding behavior estimations by di Virgilio et al. [41], we may expect that each of our tracked individuals to disperse up to 405 seeds per night (under ideal conditions). Considering an average gut passage time of $30 \mathrm{~min}$ [ 42 and personal observations], feeding periods of $15 \mathrm{~min}$ neighboring mistletoes [40] and an average movement speed of $1.45 \mathrm{~m} / \mathrm{min}$ (this study), we estimated an average seed dispersal distance of $43.68 \mathrm{~m}$.

\section{Conclusions}

In summary, D. gliroides home range and core areas at our study site showed large variability, but this is consistent with previous research on this marsupial. We found no significant differences in the movement behavior between males and females [being consistent with 15], nor between sub-adults and adults, despite significant variation in body mass, suggesting that home range differences might be more attributable to extrinsic factors. Also, tracked D. gliroides individuals moved faster at the beginning of their activity period, but reached its lowest speed during its peak activity period, contrary to our expectations. However, such movement pattern is consistent with a recent study of $D$. gliroides feeding behavior [41], suggesting that they concentrate fruit manipulation and consumption between 01:00 and 03: $00 \mathrm{~h}$, moving shorter distances among fleshy-fruited plants [41]. Despite its key ecologic role as primary seed disperser in South American temperate rainforests, the behavior of $D$. gliroides remains poorly known. We encourage future studies on this subject, as behavioral information is necessary to define appropriate conservation and management actions, aiming to protect this relict species thriving into a vanishing habitat.

\section{Supplementary information}

Supplementary information accompanies this paper at https://doi.org/10. 1186/s40693-019-0088-y.

Additional file 1: Supporting Information associated to this article contains: Accumulation curves showing the effect on increasing number of locations on home range and core area estimations (Figure S1.), home range (Figure S2.) and core areas (Figure S3.) of tracked Dromiciops gliroides individuals; core area overlap between adult males and females (Figure S4.) and between adults and sub-adults (Figure 
S5.): detailed GLM results of: body mass comparison between males and females, and between adults and sub-adults (Table S1.), home range and core area comparisons between males and females, and between adults and sub-adults (Table S2.), home range and core area vs. body mass relationships (Table S4.), home range and core area vs. number of locations relationships (Table S5.), and movement speed among activity periods (Table S5.).

\section{Abbreviations}

GLM: Generalized linear model; GLMM: Generalized mixed-effects linear model; KDE: Kernel density estimator

\section{Acknowledgements}

We thank P. Muñoz (RIP), ranger of the San Martin Experimental Forest (Universidad Austral de Chile). We are also grateful to G. Ortega, K. Barrientos, C.P. Silva, J.L. Bartheld and C. Suazo for their assistance during the telemetry fieldwork. We appreciate comments of D.A. Kelt and two anonymous reviewers, which largely improved an earlier version of this manuscript.

\section{Conflict of interest}

The authors declare that they have no competing interests.

\section{Author's contributions}

LMF designed the study and conducted the research. LMF and MSG conceived the idea. LMF and GG collected field data. FEF analyzed the data and led manuscript writing with contributions of LMF, GG and MSG. LMF and MSG provided considerable resources for the research. All authors read and approved the final manuscript.

\section{Funding}

Funding was provided by Idea Wild, Banco Bilbao Vizcaya Argentaria Foundation, and the Rufford Small Grants Foundation (granted to LMF). LMF thanks Universidad de Ibagué project 14-320-INT. FEF was supported by FONDECYT project 11160152.

\section{Availability of data and materials}

Original data associated with this manuscript can be accessed from the figshare digital repository: https://doi.org/10.6084/m9.figshare.6807470

\section{Ethics approval and consent to participate}

Not applicable.

\section{Consent for publication}

Not applicable.

\section{Author details \\ ${ }^{1}$ Facultad de Ciencias Naturales y Matemáticas, Universidad de Ibagué, Carrera 22 Calle 67, Ibagué 730001, Colombia. ${ }^{2}$ Instituto de Biología, Pontificia Universidad Católica de Valparaíso, Av. Universidad 330, 2373223 Valparaíso, Chile. ${ }^{3}$ Grupo de Investigación en Zoología (GIZ), Departamento de Biología, Facultad de Ciencias, Universidad del Tolima, Barrio Santa Helena, Ibagué 730006, Colombia. Instituto de Ciencias Ambientales y Evolutivas, Universidad Austral de Chile, Independencia 613, 5110566 Valdivia, Chile.}

Received: 29 July 2019 Accepted: 24 October 2019 Published online: 08 November 2019

\section{References}

1. Danchin E, Giraldeau LA, Cézilly F. Behavioural ecology: an evolutionary perspective on behaviour. New York: Oxford University Press; 2008.

2. Foster SA. Evolution of behavioural phenotypes: influences of ancestry and expression. Anim Behav. 2013;85(5):1061-75.

3. Healy TM, Schulte PM. Phenotypic plasticity and divergence in gene expression. Mol Ecol. 2015;24(13):3220-2.

4. Turcotte MM, Levine JM. Phenotypic plasticity and species coexistence. Trends Ecol Evol. 2016;31(10):803-13.

5. Foster SA, Wund MA, Baker JA. Evolutionary influences of plastic behavioral responses upon environmental challenges in an adaptive radiation. Integr Comp Biol. 2015;55(3):406-17.
6. Leite MD, Galliez M, Queiroz TL, Fernandez FAS. Spatial ecology of the water opossum Chironectes minimus in Atlantic Forest streams. Mamm Biol. 2016; 81(5):480-7.

7. Tucker MA, Ord TJ, Rogers TL. Evolutionary predictors of mammalian home range size: body mass, diet and the environment. Glob Ecol Biogeogr. 2014; 23(10):1105-14.

8. Ji WH, White PCL, Clout MN. Contact rates between possums revealed by proximity data loggers. J Appl Ecol. 2005;42(3):595-604.

9. Eccard JA, Meyer J, Sundell J. Space use, circadian activity pattern, and mating system of the nocturnal tree rat Thallomys nigricauda. J Mammal. 2004;85(3):440-5.

10. Franco M, Contreras C, Place NJ, Bozinovic F, Nespolo RF. Leptin levels, seasonality and thermal acclimation in the Microbiotherid marsupial Dromiciops gliroides: does photoperiod play a role? Comp Biochem Phys A. 2017;203:233-40.

11. Franco M, Quijano SA, Soto-Gamboa M. Communal nesting, activity patterns, and populations characteristics in the near-threatened Monito del monte Dromiciops gliroides. J Mammal. 2011;92(5):994-1004.

12. Pretzlaff I, Rau D, Dausmann KH. Energy expenditure increases during the active season in the small, free-living hibernator Muscardinus avellanarius. Mamm Biol. 2014;79(3):208-14.

13. Hershkovitz P. Dromiciops gliroides Thomas, 1894, last of the Microbiotheria (Marsupialia), with a review of the family Microbiotheriidae. Fieldiana Zool. 1999;93:1-60

14. Fontúrbel FE, Franco M, Rodríguez-Cabal MA, Rivarola MD, Amico GC. Ecological consistency across space: a synthesis of the ecological aspects of Dromiciops gliroides in Argentina and Chile. Naturwissenschaften. 2012;99:873-81.

15. Fontúrbel FE, Silva-Rodriguez EA, Cardenas NH, Jimenez JE. Spatial ecology of Monito del monte (Dromiciops gliroides) in a fragmented landscape of southern Chile. Mamm Biol. 2010;75(1):1-9.

16. Salazar DA, Fontúrbel FE. Beyond habitat structure: landscape heterogeneity explains the Monito del monte (Dromiciops gliroides) occurrence and behavior at habitats dominated by exotic trees. Integr Zool. 2016;11:413-21.

17. Kelt DA, Van Vuren $\mathrm{DH}$. The ecology and macroecology of mammalian home range area. Am Nat. 2001;157(6):637-45.

18. Muñoz-Pedreros A, Lang BK, Bretos M, Meserve PL. Reproduction and development of Dromiciops gliroides (Marsupialia: Microbiotheriidae) in temperate rainforests of southern Chile. Gayana. 2005;69(2):225-33.

19. Fontúrbel $F E$, Candia AB, Botto-Mahan C. Nocturnal activity patterns of the Monito del monte (Dromiciops gliroides) in native and exotic habitats. J Mammal. 2014;95(6):1199-206.

20. Murúa R, Briones M. Abundance of the sigmodont mouse Oligorizomys longicaudatus and patterns of tree seeding in Chilean temperate forest. Mamm Biol. 2005;70:321-6.

21. Luebert F, Pliscoff P. Sinopsis bioclimática y vegetacional de Chile. Santiago de Chile: Editorial Universitaria; 2006.

22. Olson DM, Dinerstein E. The global 200: a representation approach to conserving the Earth's most biologically valuable ecoregions. Conserv Biol. 1998;12(3):502-15.

23. Rüger N, Gutierrez AG, Kissling WD, Armesto JJ, Huth A. Ecological impacts of different harvesting scenarios for temperate evergreen rain forest in southern Chile - a simulation experiment. Forest Ecol Manag. 2007;252(1-3):52-66.

24. Echeverría C, Huber A, Taberlet F. Estudio comparativo de los componentes del balance hídrico en un bosque nativo y una pradera en el sur de Chile. Bosque. 2007;28:271-80

25. Fontúrbel FE. A methodological approach to assess the small mammal community diversity in the temperate rainforest of Patagonia. Mamm Biol. 2010;75:294-301.

26. Fontúrbel FE, Jimenez JE. Underestimation of abundances of the Monito del monte (Dromiciops gliroides) due to a sampling artifact. J Mammal. 2009; 90(6):1357-62

27. Parmenter RR, Yater TL, Anderson DR, Burnham KP, Dunnum JL, Franklin AB, et al. Small-mammal density estimation: a field comparisons of grid-based and web-based density estimators. Ecol Monogr. 2003;73(1):1-26.

28. Sikes RS. Animal care use Committee of the American Society of Mammalogists. 2016 guidelines of the American Society of Mammalogists for the use of wild mammals in research and education. J Mammal. 2016;97(3):663-88.

29. Harris S, Cresswell WJ, Forde PG, Trewhella WJ, Woollard T, Wray S. Homerange analysis using radio-tracking data-a review of problems and techniques particularly as applied to the study of mammals. Mammal Rev. 1990;20(2-3):97-123. 
30. Saltz D. Reporting error measures in radio location by triangulation: a review. J Wildl Manag. 1994;58:181-3.

31. Calenge $C$. The package adehabitat for the R software: a tool for the analysis of space and habitat use by animals. Ecol Model. 2006;197:516-9.

32. Development R. Core team. R: a language and environment for statistical computing, reference index version 3.5.1. Vienna, Austria: Foundation for Statistical. Computing. 2018.

33. Beckerman AP, Childs DZ, Petchey OL. Getting started with R: an introduction for biologists. Second edition ed. New York: Oxford University Press; 2017.

34. Zuur A, leno EN, Walker N, Saveliev AA, Smith GM. Mixed effects models and extensions in ecology with R. New York: Springer; 2009.

35. Halekoh U, Højsgaard S. A Kenward-Roger approximation and parametric bootstrap methods for tests in linear mixed models - the R package pbkrtest. J Stat Softw. 2014;59(9):1-30.

36. Bates $\mathrm{D}$, Maechler M, Bolker B. Ime4: Linear mixed-effects models using $\mathrm{S} 4$ classes. R package version 0.999375-39. http://CRAN.R-project.org/package= Ime42013.

37. Kusnetzova A, Brockhoff PB, Haubo R. ImerTest: Test in Linear Mixed Effects Models. $\mathrm{R}$ package version 2.0-25. http://CRAN.R-project.org/package $=$ ImerTest2015.

38. Wickham H. ggplot2: elegant graphics for data analysis. New York: Springer; 2016

39. Cáceres NC. Use of the space by the opossum Didelphis aurita (Mammalia, Marsupialia) in a mixed forest fragment of southern Brazil. Rev Bras Zool. 2013;20:315-22.

40. Fontúrbel FE, Salazar DA, Medel R. Why mistletoes are more aggregated in disturbed forests? The role of differential host mortality. Forest Ecol Manag. 2017:394:13-9.

41. di Virgilio A, Amico GC, Morales JM. Behavioral traits of the arboreal marsupial Dromiciops gliroides during Tristerix corymbosus fruiting season. J Mammal. 2014;95(6):1189-98.

42. Amico GC, Rodríguez-Cabal MA, Aizen MA. The potential key seeddispersing role of the arboreal marsupial Dromiciops gliroides. Acta Oecol. 2009;35:8-13.

43. Mora JP, Soto-Gamboa M. Legitimate seed dispersal Ugni molinae Turcz. (Myrtaceae), by Monito del monte, Dromiciops gliroides. Gayana Bot. 2011; 68(2):309-12.

44. Morales JM, Rivarola MD, Amico GC, Carlo TA. Neighborhood effects on seed dispersal by frugivores: testing theory with a mistletoe-marsupial system in Patagonia. Ecology. 2012;93:741-8.

45. Sasal Y, Morales JM. Linking frugivore behavior to plant population dynamics. Oikos. 2013;122:95-103.

46. Amico GC, Rodríguez-Cabal MA, Aizen MA. Geographic variation in fruit colour is associated with contrasting seed disperser assemblages in a southAndean mistletoe. Ecography. 2011;34(2):318-26.

\section{Publisher's Note}

Springer Nature remains neutral with regard to jurisdictional claims in published maps and institutional affiliations.

Ready to submit your research? Choose BMC and benefit from:

- fast, convenient online submission

- thorough peer review by experienced researchers in your field

- rapid publication on acceptance

- support for research data, including large and complex data types

- gold Open Access which fosters wider collaboration and increased citations

- maximum visibility for your research: over $100 \mathrm{M}$ website views per year

At $\mathrm{BMC}$, research is always in progress.

Learn more biomedcentral.com/submissions 